\title{
Development of Maritime Professionals in Bangladesh: A Literature Review
}

\author{
Mohammad Morad Hossain ${ }^{1}$, Prof. Dr. Md. Nazrul Islam² \\ ${ }^{1}$ M.Phil Researcher, Bangladesh University of Professionals \\ ${ }^{2}$ Pro-Vice Chancellor, Northern University Bangladesh
}

\begin{abstract}
Bangladesh has a rich shipping history. The country is dependent economically as well as socially and politically on the industry. While, the country is slowly regaining global recognition, the industry is no less on challenges. The seafarers face major issues due to the factors such as conditions of the maritime education and training institutes, forged documentation, negative reputation of the country, etc. Further, the seafarers of Bangladesh also lack skills and training when compared to the seafarers of the other developed countries. Moreover, the country lacks technological resources too, which makes it even more difficult for the seafarers to grow in the industry. The article looked at the different sets of improvements that can be made to the shipping industry and make it easy for the seafarers to get proper jobs in the industry. This study explored the challenges and opportunities for the seafarers and the industry though a review of literature.
\end{abstract}

Keywords: Bangladesh, shipping industry, seafarers, Maritime Education and Training, challenges and opportunities

\section{Introduction}

Bangladesh has a historical relationship with the shipping industry. Yet, the country hasn't grown with the same speed as it should have. Problems such as lack of infrastructure, financial issues, absence of proper education and training, etc. have affected the growth of the shipping industry in Bangladesh. Nonetheless, with establishment of various Maritime Education and Training Institutes (MET's) and investment in infrastructure, the situation of the shipping industry has improved in the country. It must be noted that the shipping industry has grown immensely in the South-East Asian countries such as Bangladesh and India. More than $90 \%$ trade of the country is carried through waterways (Alam, 2014). The country has also had a long tradition of supplying seafarers. The gap between the demand and supply of seafarers has opened further opportunities for these seafarers in the shipping industry.

The challenges of seafarers aren't hidden from anyone. The Bangladeshi seafarers face problems like use of forged documents, negative reputation of the country abroad, etc. The government has looked into this matter now, and the situation has improved. Furthermore, the earnings of the seafarers of the country is an issue too. The seafarers of Bangladesh are paid much less as compared to the seafarers of other countries (Begum, 2013). But the seafarers of Bangladesh are also considered as one of the most hardworking, truthful and quick learners when compared to the other nations (Zakaria et al, 2010), hence, proper training and education, along with the support of government can help these seafarers and also motivate the coming generations to build their career in the shipping industry. The job of seafaring is also dangerous at the same time. Various fatalities and injuries have been caused due to the same. Some of the major causes of such accidents are overloading and collision, etc (Awal, 2006 and Awal et al, 2007).

While the shipping industry has been the major topic of discussion, the study has also looked into the other related activities. It has been suggested in the previous studies to combine the ship recycling industry with the shipping industry for proper growth and working. The vessel grounding in 1964, along with requirements to remove the wreck after the Pakistan War in 1971 led to the emergence of the ship recycling industry in the country of Bangladesh (FIDH et al, 2008). It must also be noted that the ship recycling industry has massively grown in the region of South Asia, especially in countries like India, Bangladesh, etc. 
While these countries contribute around 70-80 percent of the total international market, China and Turkey account for most of the left part (Hossain et al, 2010).

The main aim of this paper was to enlist and explore the various challenges faced in the development of maritime professionals. Furthermore, the study also tried to ascertain the different opportunities existing in the sector for the development of maritime professionals.

\section{Literature review}

\section{Seafarers and Shipbuilding Prospects}

Islam et al, (2019) analysed the situation of the workforce involved in the shipping industry. The objective was to identify the condition of the Maritime Education and Training Institutions (MET) in the context of Bangladesh. There are some reasons for unemployment of sea-farers which includes shortage of national flag vessels, the reputation of the country at a global stage as well as the situation of the Maritime Educational Institutions in the country for the same, Alamgir (2001) and Ziauddin (2017) discussed the existence of inhabitants, and the growth as well as problems arising in the shipping industry during all of this timeframe. Focusing on the Maritime Education and Training Institutes of Bangladesh, there are some issues like-lack of synergy between the various MET Institutes, absence of controlling body, shortage of qualified and trained faculties. However, various different METs have opened in the country with better faculties (Kabir,2014). Kabir mentioned the prospects for Bangladesh in METs which includes establishment of BSMRMU and MAU (Maritime Affairs Unit) etc. In addition to that Ziauddin and Chowdhury (2019) mentioned various steps such as declaration of BSMRU as a central university for MET, conversion of MAU into Ministry of Maritime Affairs which help to better the conditions, the practicality of such recommendations are still to worry about. However Islam et al, (2019) also emphasized on these steps and Hassan (2006) stressed on the situation of seafarers in Bangladesh shipping industry. Whereas Saha (2016) emphasized on the laws of International Labour Convention to improve the conditions prevailing there. Shemon et al, (2019) was focused on recruitment processes and its effectiveness along with emphasising importance of training.

There are some factors, which were identified by the researchers like labour skills, availability of labour, labour cost and productivity. Apart from this there are other factors like- local shipbuilding, wage costs, knowledge, capital, raw materials and manpower input, skills possessed and employment, which plays a vital role by the local entrepreneurs in the gradual success of shipping industry in Bangladesh (Zakira et al, 2010). But lack of Research and development, infrastructure (Rahman, 2017) acts as a barrier in the growth of industry in Bangladesh. In addition to that Iqbal et al, (2010) found issues that pose barriers for growth. Issues like financial problems, technical issues, quality control problems, which lead to slow down the growth of the shipbuilding industry (Ibid). Shemon (2005) emphasized on generating demand in the local as well as in the foreign markets and, enhancement in the skills of the sea farers and everyone involved in the industry. Saha (2016) \& Hossain and Zakaria et al, (2017) looked into the steps that could be taken by the government in development of the industry, such as formulation of policies, building a climate that suits right for the investment purposes from local as well as foreign entrepreneurs.

Maritime shipping industry is a complex system, which is composed of various integral parts that are independent and are in a constant search, and try to learn as well as adapt to the environment (Caschili and Medda 2012). They further mentioned the different kinds of independent agents which were rational in nature such as port authorities, providers of shipping services, various different shipping companies, etc. Through this research, the authors have tried to define shipping industry from the view of Complex Adaptive System (CAS). The study emphasized on improvement in the technical field, growth in the fields of logistics reorganization, and these are the major reasons behind the development of CAS in the maritime shipping industry. The challenge still remains are the setup of this system, which is still out of practicality.

There are two new algorithms that are addressed by Rahman and Haque (2014) to make improvements in the process of weather forecasting which could be implemented and applied in the Meteorological Department of Bangladesh (BMD). The study identified how these algorithms help in determining the best range of the wind speed, which further assist inhabitants living near coastal regions and to make them aware of the danger coming towards them. Further it stated that, scope of these algorithms wasn't just limited to 
the wind speed, but could further be diversified to other parameters such as direction of the wind, temperature, etc. Thus, it concluded that, the introduction of new equipment and technology has further increased the scope and collaborations of BMD with CPP. In a similar fashion, Biswas et al, (2014) analysed the demand of power generation in Bangladesh. The study emphasized on the instability in the demand and supply concept of power. It was suggested that utilization of solar energy reduce the issue of wide gap between the power demand and supply. Whereas, development of renewable sources of energy is recommended by the researchers to improve the conditions. The situation of navigational aspect of marine transport and its requirement of having a precise knowledge on the topic of tides, Rose and Bhaskaran (2015) found that proper knowledge on the tides can be used to explore works in the field of coastal engineering. The study further cited the development of Sea Level Processing Package (SLPR2) so as to come up with the correct estimate of location specific sea level information. The researchers concluded that SLPR2 is a satisfactory mean to perform a tidal analysis.

Modern engineering technologies such as Logic Program Technique (LPT) could be developed and utilized to decrease the intensity of maritime accidents (Awal and Hasegawa, 2017). Raiyan, Das and Islam (2017) identified the factors which lead to accidents and it found that one of the major reasons behind marine accidents is the lack of clear visibility. Rahman (2017) revealed that, marine accidents affect surroundings as well as humans and activities of shipping industry. Common causes of marine accidents are collision, contacts, explosions and fire, rough weather, bad and foggy weather, etc. (Uddin, Awal, Islam and Newaz, 2017).

\section{Challenges faced in the Development of Maritime Professionals in Bangladesh}

Haque et al, (2017) examined climate adaptation in the Sylhet Division of the country of Bangladesh. Study explained the challenges faced in mobilising high quality knowledge in the favour or support of climate adaptation. Moreover, these issues about the knowledge quality can prove out to be serious in vulnerable countries like Bangladesh. Further, researchers explored the numerous challenges in adaption of high quality knowledge which means climate adaption based on best quality knowledge is available but, in Bangladesh adaption becomes difficult because of lack of skills in the concerned people. Study shows that KQA (knowledge quality assessment) is significant pre- requisite for climate adaption. Whereas, Bangladesh climate adaption policy emphasis on scientific knowledge. Thus, policies have influenced the framing of climate adaptation. Sovacool (2018) stated that natural disaster such as flood etc caused tension because of changes in the climatic conditions. Ashrafuzzaman and Furini (2019) explored the measures that could be taken by the government in decreasing pollution. The study mentioned salinity as major cause of pollution as a result of climatic changes. Hasan et al, (2019) found that "lack of proper monitoring, poor implementation of laws as well as lack of modern treatment plants and water supply systems, and poor awareness and education about water use and safety are the main prompt of water pollution in Bangladesh". Wave wash is defined as a hydrodynamic tool which is used to explain the waves generated by ships and its effect on the shore as well as shore erosion (Saha et al, 2017). The paper aimed to describe wave wash as one of the most integral factors in imposing restrictions on the maximum speed of the ship as well for the purpose of selecting the speed for any shallow or narrow waterway. The study proposed to look into the importance of consideration of wave wash in the operation of the ship as well as the design of the ship. The researchers mentioned the problem of water shortage all round year (Shamsuzzoha et. al, 2018; Ghosh 2018). Furthermore, this issue becomes more critical during the dry season. It is further noted that the reverse osmosis technology is one of the most technical and economically feasible source of drinking water. At the same time, this technology would also play an integral role as a disaster risk reduction (DRR) based solution with respect to the problem of shortage of drinking water (Ibid). There are some issues in district and sub-district government health care facilities of Bangladesh in managing burn injuries (Biswas et. al, 2020). This problem is more complicated as the treatment costs for burn patients including specialized personnel and technologies are not always readily available in low income countries. The study found out that healthcare facilities didn't have proper equipment, medicines or logistics and doctors and nurses weren't trained enough to handle burned patients. However the "Ministry of Health and Family Welfare of Bangladesh" can play a vital role by developing and implementing guidelines, training health professionals, ensuring availability of logistics and modifying the infrastructure of the facilities for burn-injured patients. Chemicals such as nitrofuran and chloramphenicol in the farmed shrimps and prawns which had become a 
major concern in the export industry of Bangladesh (Hassan et. al. 2013). The utilization of these banned antibiotics had led to rejection of the consignments from the foreign buyers. The point to be noted was that it was mentioned that the farmers didn't use these antibiotics consciously, but rather these were detected in various samples of M. rosembergil, and P. monodon in 2008, 2009 and 2010. But with proper testing of the samples, and proper steps, the export consignments had undergone significant changes, whereby there had been a decrease in the amount of these antibiotics. Mannan et. al, (2014) wrote about the resistance pattern as well as the sensitivity of the samples of Salmonella typhi to the popularly used antibiotics in Bangladesh. They further tried to evaluate the developing pattern of resistance. They also mentioned the damage caused due to diseases such as typhoid and paratyphoid and, identified them as one of the major health issue in the country of Bangladesh. Ahsan et. al, (2020) carried out the study on Cyclone early warning systems in Bangladesh. They focused on estimating the willingness to pay (WTP) for improved warning services between proposed improved EWS and existing EWS in coastal Bangladesh. Results suggested that coastal households who were at risk have showed their willingness to pay for the proposed improved EWS over the existing one. Ahmad (2019) conducted a study to understand the scenario of coastal zone management and its future trends in Bangladesh. "Coastal Zone $(\mathrm{CZ})$ is the region where land, ocean and atmosphere interact with each other hence it is dynamic and diverse in nature." And this zone is being continually attacked by cyclones, storms etc. which have negatively impacted this region.CZ of Bangladesh requires an integrated management to achieve mutual interaction among coastal community, policies and in its sustainable development plans. Rahman and Rahman (2015) referred to the natural disasters such as cyclones, floods, tidal surges, salinity intrusion and erosion, etc. in the coastal regions of Bangladesh in the study. These regions are the most populated ones in the country. The researchers further mentioned about the problems caused by these natural disasters, such as large scale damage of property, lives, damage of crops, etc.

\section{Blue Economy}

Hussain, Failler and Sarker (2019) explored the opportunities of employment, economic growth as well as the opportunities in improving the health of the oceans and waterways of the world. They further analysed the sustainability level achieved through the concept of Blue Economy. Water bodies in the country of Bangladesh are used for various purposes such as fisheries, and for the collection of various living resources as well as for different land- based activities such as tourism and development, for extraction of the nonliving resources, etc. Rahman (2017) explored the concept of Blue Economy. The study concentrated on the Bay of Bengal and the maritime cooperation. It was further mentioned in the study that a sustainable utilization of resources, both living and non-living will help leverage employment, development on the front of both social and economic as well as help in reducing the problem of food security in Bangladesh, especially the regions around Bay of Bengal. The situation of the theory of Blue Economy can be improved through effective legal and governance regime, and revaluation of the previous laws. Bari (2017) emphasized that while the term Blue Economy is still new to the countries of South-East Asia, there are different ways through which it could be practiced in such countries, especially the ones of the Indian subcontinent. The study also analysed the opportunities for growth of business activities in and around the sea. Hence, it recommended using the marine resources carefully. These countries need to make strong political commitments, make the society aware and develop the $\mathrm{R} \& \mathrm{D}$, so as to help the country become a Blue Economy. Hussain, Failler, Karim and Alam (2017) analysed the limitations of the country in achieving this theory practically. The government of the country has moved forward towards achieving the Blue Economy by initiating talks with the various stakeholders. The major objectives of this theory, according to the researchers is exploiting the potential of the marine sources with the help of solutions as well as technical innovations for the purpose of providing food security, creating jobs, for trade purposes, etc. To achieve these objectives, the researchers mentioned the importance of government policies which can prove out to be the game changer.

\section{Challenges and opportunities}




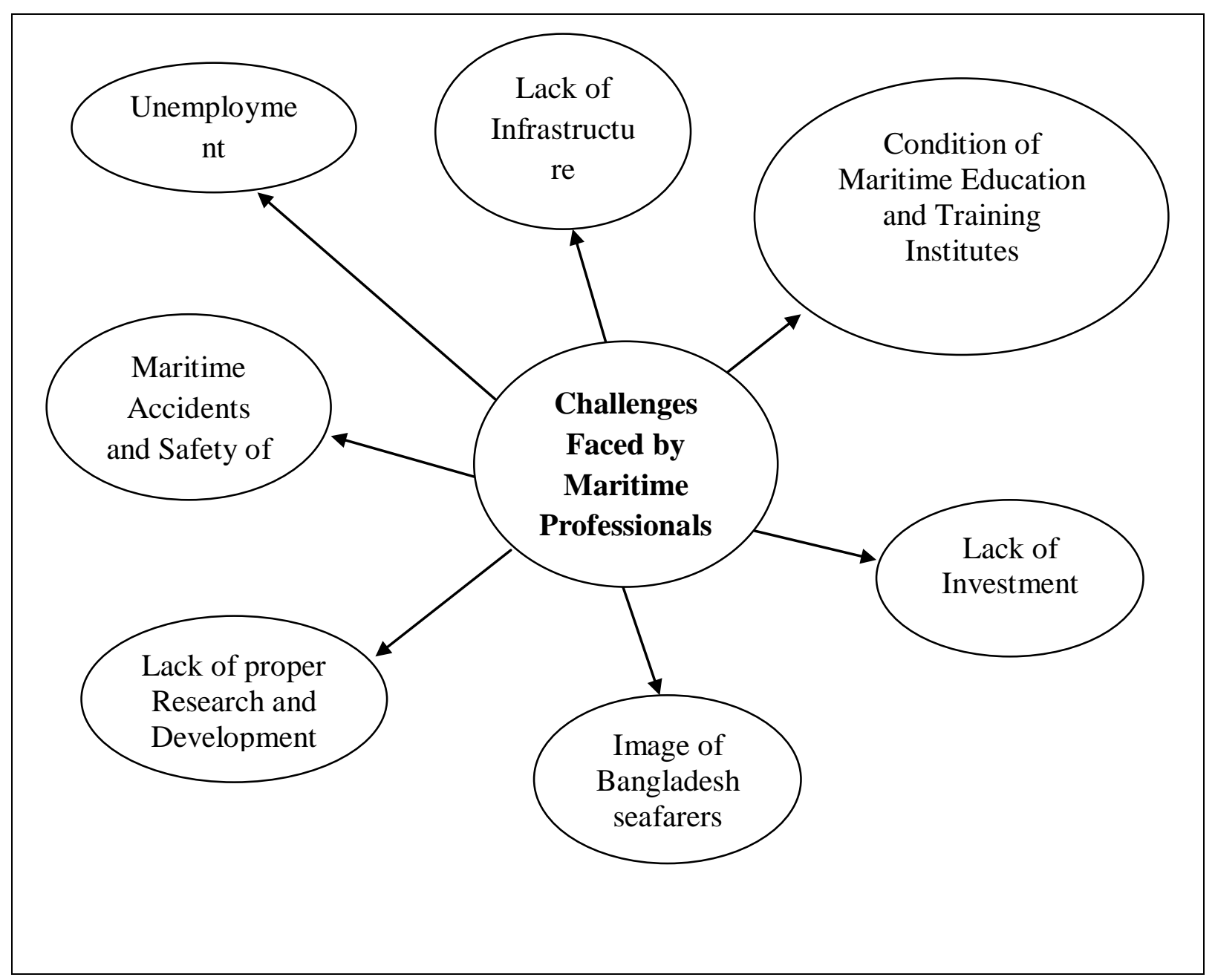

Figure 1: Challenges faced by Maritime Professionals

\section{Challenges Identified Through Review of Literature}

Unemployment: The shipping industry faces the problem of unemployment which is the result of improper training and low wages for the seafarers (Islam et al, 2019).

Lack of Infrastructure: Bangladesh faces the issue of lack of infrastructure in the country. The country is still counted as one of the developing countries, and the entrepreneurs, both from abroad as well as local, lack on providing better infrastructure to the country (Iqbal et al, 2010).

Condition of Maritime Education and Training Institutes: Though the institutes have been established in the country, they lack in terms of providing the right skills and training to the seafarers, which ultimately affects the employment of the seafarers (Alamgir, 2001 and Kabir, 2014).

Maritime Accidents and Safety of Employees: Maritime accidents and safety of employees tend to become one of the most crucial challenges in shipping industry in Bangladesh. These accidents affect the industry not only economically, but socially as well (Awal and Hasegawa, 2017). The major reasons behind such accidents have known to be collision, overloading, etc. (Rahman, 2017).

Lack of Investment: As mentioned earlier, the country lacks investment in terms of infrastructure, which makes it behind other developed countries in the world (Shemon, 2005).

Lack of Research and Development: Bangladesh lacks on the subject of proper research and development in the shipping industry (Zakaria et al, 2010).

Quality Control Problem: The issue of quality control makes it difficult for the shipping industry to grow efficiently in Bangladesh (Iqbal et al, 2010).

Image of Bangladeshi Seafarers: The image of Bangladeshi seafarers abroad becomes a challenge to the growth of shipping industry in the country (Hassan, 2006). The use of false documents and forged visa often leads to distrust in the Bangladeshi employees (Hassan, 2006). 


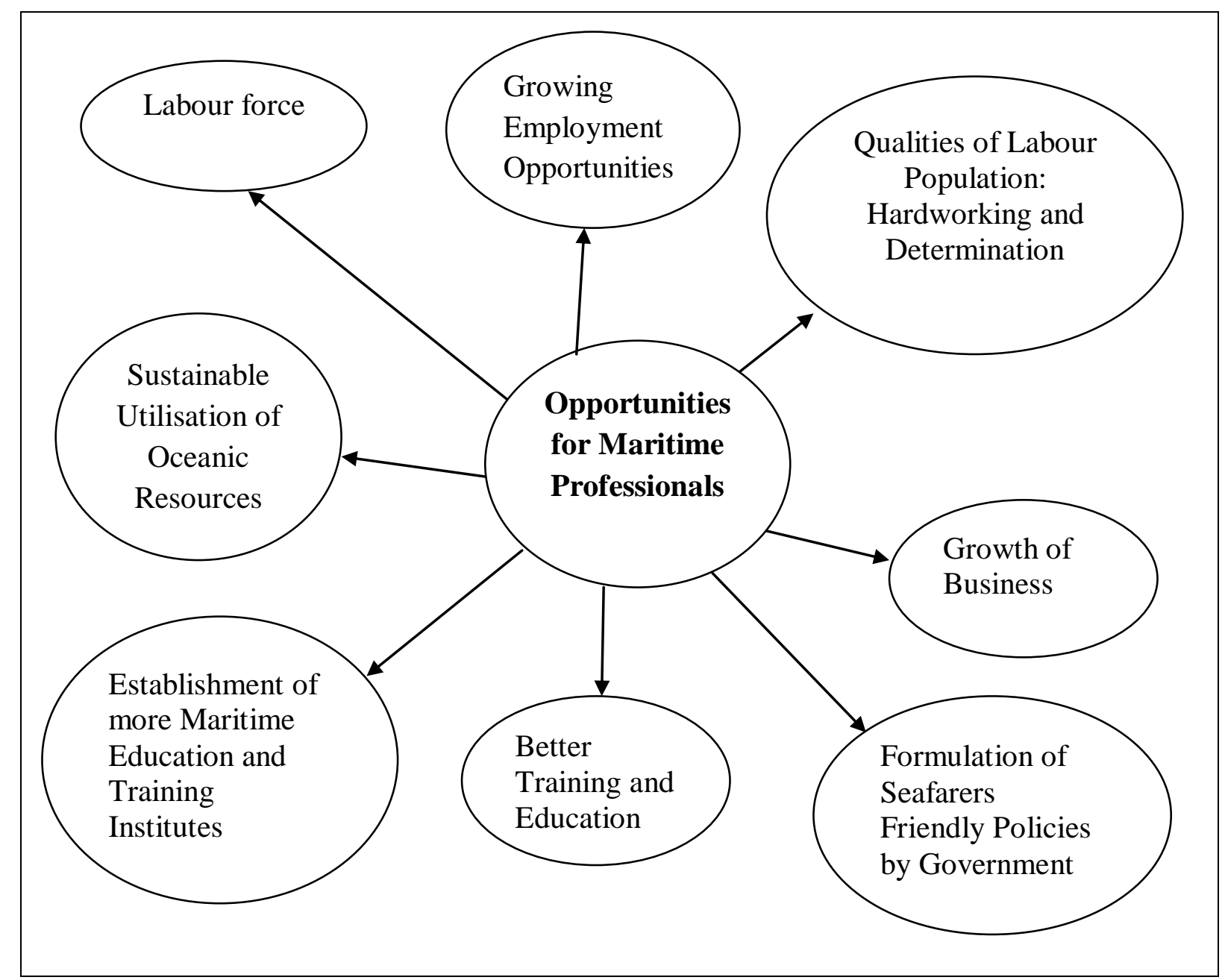

Figure 2: Opportunities for Maritime Professionals

\section{Opportunities Identified Through Review of Literature}

Labour force: Bangladesh is densely populated, and a large chunk of the population consists of youth, which tends to provide large workforce for the shipping industry, which ultimately turns out as an opportunity for the country to spread its arms in the direction of growth of shipping industry (Hasan et al, 2017 and Hassan, 2006).

Qualities of Labour Population: While the labour force provides an opportunity for growth of shipping industry in Bangladesh, the characteristic behaviour of this labour force affects the shipping industry in a positive manner (Hassan, 2006). The Bangladeshi seafarers are considered to be the most hardworking and determined labour force.

Growing Employment Opportunities: There has been a jump in the growth of jobs and employment in the industry (Hussain et al, 2019). The same has happened due to formulation of proper policies as well as by providing proper training to the seafarers (Islam et al, 2019).

Sustainable Utilisation of Resources: The introduction of Blue Economy has led to the understanding of proper utilisation of resources in a sustainable method, which opens the opportunity of growth in future (Bari, 2017 and Rahman, 2017).

Establishment of MET's: The establishment of MET's have provided the seafarers with proper training and skills in the recent times, which makes it easier for seafarers, thereby increasing the employment opportunities (Alamgir, 2001).

Better Training Opportunities: The MET's in the recent times have recruited better faculty, which emphasize on providing the seafarers with better skills, techniques, etc. (Alamgir, 2001).

Formulation of Seafarer Friendly Policies: The government of Bangladesh has paid specific attention towards the issues of the seafarers, and have tried to come up with better policies for them, thereby making it easy for them to get employed as well as make them more skilled and trained (Alamgir, 2001 and Shemon, 2005). 


\section{Discussion and Conclusion}

The existing studies showed that Bangladesh has had a historic relationship with the shipping industry; the country is still facing various problems such as lack of infrastructure, lack of R\&D, lack of trained seafarers, etc. The study mentions while various Maritime and Education Trainings have been established, still a lot has to be done to reach a good position. Bangladesh is a populated country, and just like every other SouthEast Asian country, the labour here too is cheap, which provides a certain edge to the country.

It has been observed from that the job opportunities in the shipping industry are expected to decrease. Literature reviews from the existing studies exposed fact that lot of seafarers have already lost their jobs at a global level (Hassan, 2018). This paper also noted that Bangladesh has the potential to develop and explore opportunities in the seafaring jobs from its public as well as private academies if it is able to provide them with on board training which hadn't been mentioned in the other papers before. Furthermore, Bangladesh also has the potential to turn itself into a hub of the shipbuilding industry in the global context for both small as well as medium sized vessels (Zakaria et al, 2010). The country has advantages like its geographical location and cheap labour, which makes it a nation of a lot of potential in terms of growth of the shipping industry. Foreign Direct Investment (FDI) is one of the most integral factors in the development of the shipping industry in Bangladesh. Liberal investment policy along with incentive regime is considered as essence of getting a steady inflow of FDI in Bangladesh (United Nations Economic and Social Commission for Asia and Pacific, 2015).

The problems of maritime accidents too cause concern. It is found that the common causes of maritime death were fire, explosion, overloading, etc (Rahman, 2017).Amidst all of this, the theory of Blue Economy becomes more important and broad. In the process of achieving Blue Economy, a co-ordinated approach is required with a concerned group of stakeholders so as to determine the extent to which the constraints can be converted into opportunities. (Hussain et al, 2019).

The present study attempted to study the potential and prospects of the growth in the shipping industry. Based on the previous literatures, the paper tried to analyse and explore the developments and challenges in the shipping industry and other related activities and brought into new concepts and explorations of the same. The study would prove to be helpful for entrepreneurs as well as the government in providing investments in the industry in the country as well as formulating plans and policies for the betterment of MET's and lives of the seafarers. The same would also prove out to assist in promoting ideas to reduce the number of maritime accidents in the country; thereby providing a safe environment for the seafarers of the country.

\section{References:}

[1] Ahmad, H. (2019). Bangladesh Coastal Zone Management Status and Future Trends. Journal of Coastal Zone Management, 1-6.

[2] Ahsan, Md. N., Khatun, A., Islam, Md. S., Vink, K., Ohara, M. \& Fakhruddin, B. S.H.M. (2020). Preference for improved early warning signals among coastal communities at risk in cyclone prone south-west region of Bangladesh. Progress in Disaster Science, 1-11.

[3] Alam, M.K. (2014). Ocean/Blue economy for Bangladesh. In: Proceedings of International Workshop on Blue Economy, Ministry of Foreign Affairs, Dhaka, Bangladesh, 28-49.

[4] Alamgir, M. (2001). Problems and Prospects of Maritime Education in Bangladesh. British Medical Journal, 1-11.

[5] Ashrafuzzaman, M. \& Furini. G.L. (2019). Climate change and human health linkages in the context of globalization: An overview from global to southwestern

[6] Awal, Z., I. \& Hasegawa, K. (2017). A Study on Accident Theories and Application to Maritime Accidents. Procedia Engineering, 298-306.

[7] Awal, Z.I, Islam, M.R. \& Hoque, M., (2007), Marine Vehicle Accident Characteristics in Bangladesh: Study on Collision Type Accidents, ICME-2007, Dhaka, Bangladesh. 
[8] Awal, Z.I. (2006) A study on inland water transport accidents in Bangladesh: Experience of a decade (19952005), Proceedings of the International Conference on Coastal Ships and Inland Waterways.

[9] Bari, A. (2017). Our Oceans and the Blue Economy: Opportunities and Challenges. Procedia Engineering, 5-11.

[10] Begum, H. (2013). The Role of Maritime Cluster in Enhancing the Strength and Development of Maritime Sectors of Bangladesh.

[11] Biswas, A., Abdullah, A.S. Md., Deave, T., Dalal, K. And Mashreky, S.R. (2020). Exploration of gaps and challenges in managing burn injury at district and sub-district government health care facilities in Bangladesh. Burns Open, 16-21.

[12] Biswas, A.K., Sajjakulnukit, B. \& Rakkwamsuk, P. (2014). Subsidy Policy Instruments for Rapid Growth of Photovoltaic Electricity Generation in Bangladesh. Energy Procedia, 68-76.

[13] Caschili, S. \& Medda F. (2012). A Review of the Maritime Container Shipping Industry as a Complex Adaptive System. Interdisciplinary Description of Complex System- Scientific journal, 115.

[14] Haque, M.M., Bremer, S., Aziz, S.B. \& Slujis, J.P.V.D. (2017). A critical assessment of knowledge quality for climate adaptation in Sylhet Division, Bangladesh. Climate Risk Management, 43-58.

[15] Hasan, K.R., Rahaman, M.M., Alamgir, M.Z. \& Akimoto, H. (2017). Foreign Direct Investment and the Shipbuilding Industry: A Bangladesh Perspective. Procedia Engineering, 218-223.

[16] Hasan, M.K., Shahriar, A. \& Jim, K.U. (2019). Water pollution in Bangladesh and its impact on public health. Heliyon, 1-23.

[17] Hassan, M.N. (2006). Tapping Potential of Global Demand for Seafaring Officers: An Ageda for Bangladesh. BMJ, 75-93.

[18] Hossain, K.A. \& Zakaria, N.M.G. (2017). A Study on Global Shipbuilding Growth, Trend and Future Forecast. Procedia Engineering, 247-253.

[19] Hussain, M.G., Failler, P. \& Sarker, S. (2019). Future Importance of Maritime Activities in Bangladesh. Journal of Ocean and Coastal Activities in Bangladesh, 1-17.

[20] Hussain, M.G., Failler, P., Karim, A.A. \& Alam, M.K. (2017). Major Opportunities of Blue Economy Development in Bangladesh. Journal of Indian Ocean Region, 1-12.

[21] Iqbal, K.S., Zakaria, N.M.G. \& Hossain, K.A. (2010). Identifying and Analysing Underlying Problems of Shipbuilding Industries in Bangladesh. Journal of Mechanical Engineering, 147-158.

[22] Islam, D., Ziauddin, A. \& Shaheen, M.M. (2019) a). Employment of Seafarer; Bangladesh Perspective. 69-74.

[23] Islam, M.M., Barman, A., Kundu, G.K., Kabir, M.A. \& Paul, B. (2019). Vulnerability of inland and coastal aquaculture to climate change: Evidence from a developing country. Aquaculture and Fisheries, 183-189.

[24] Kabir, M.M. (2014). Enhancement of seafarers' employability through capacity building in maritime education and training (MET): a case study of Bangladesh. 1-117.

[25] Mannan, A., Shohel, M., Rajia, S., Mahmud, N.U., Kabir, S. \& Hasan, I. (2014). A cross sectional study on antibiotic resistance pattern of Salmonella type clinical isolates from Bangladesh. Asian Pacific Journal of Tropical Biomedicine, 306-311.

[26] Rahman, M.A. \& Rahman, S. (2015). Natural and traditional defence mechanisms to reduce climate risks in coastal zones of Bangladesh. Weather and Climate Extremes, 84-95.

[27] Rahman, M.M. (2017). An Appraisal of Shipbuilding Prospects in Bangladesh. Procedia Engineering, 224-231.

[28] Rahman, M.R. (2017). Blue Economy and Maritime Cooperation in the Bay of Bengal: Role of Bangladesh. Procedia Engineering, 356-361.

[29] Rahman, S. (2017). An Analysis of Passenger Vessel Accidents in Bangladesh. Procedia Engineering, 284-290.

[30] Rahman, T. \& Haque, A.L. (2014). A Fuzzy-Neuro Based Weather Prediction System for Bangladesh. Procedia Computer Science, 606-611.

[31] Raiyan, A., Das, S. \& Islam, M.R. (2017). Event Tree Analysis of Marine Accidents in Bangladesh. Procedia Engineering, 276-283. 
[32] Rose, L. \& Bhaskaran, P.K. (2015). Tidal Prediction for Complex Waterways in the Bangladesh Region. Aquatic Procedia, 532-539.

[33] Saha, G.K., Abdullah, M.S.B. \& Ashrafuzzaman, F. (2017). Wave Wash and Its Effects in Ship Design and Ship Operation: A Hydrodynamic Approach to Determine Maximum Permissible Speed in a Particular Shallow and Narrow Waterway. Procedia Engineering, 152-159.

[34] Saha, R.C. (2016). Standardization of Maritime Education and Training in Bangladesh to Face the Global Challenges in the Seafarer's Job Market. 410-424.

[35] Shamsuzzoha, M., Rasheduzzaman, M. \& Ghosh, R.C. (2018). Building Resilience for Drinking Water Shortages through Reverse Osmosis Technology in Coastal Areas of Bangladesh. Procedia Engineering, 559-566.

[36] Shemon, W.S. (2005). Problems and Prospects of Bangladesh Shipping Industry and Comparative Overview. BMJ, 49-69.

[37] Shemon, W.S., Kabir, A. \& Hasan, K.R. (2019). Human Resource Competitiveness in Shipping Industry: Bangladesh Perspective. 251-256.

[38] Sovacool, B.K. (2018). Bamboo Beating Bandits: Conflict, Inequality, and Vulnerability in the Political Ecology of Climate Change Adaptation in Bangladesh. World Development, 183-194.

[39] Uddin, M.I., Islam, M.R., Awal, Z.I. \& Newaz, K.M.S. (2017). An Analysis of Accidents in the Inland Waterways of Bangladesh: Lessons from a Decade (2005-2015). Procedia Engineering, 291297.

[40] Zakaria, N.M.G, Rahaman, M.M. \& Hossain, K.A. (2010). Study on Some Competitive Parameters for Shipbuilding industry in Bangladesh. 413-418.

[41] Zakaria, N.M.G, Rashid, K. \& Khaled, M.I. (2017). Environmental Pollution in Bangladesh by Inland Tanker Operation. Procedia Engineering, 330-336.

[42] Ziauddin, A. \& Chowdhury, M.M.H. (2019). Maritime Education and National Economic Growth: Bangladesh Perspective. British Medical Journal (BMJ), 32-42.

[43] Ziauddin, A. (2017). Problems and Prospects of Maritime Education in Bangladesh. BMJ, 1-11. 